\title{
Prospective Evaluation of Patients Leaving against Medical Advice of a Tertiary Care Hospital: Comparison of Emergency and Intensive Care Units
}

\author{
Paul Gunchan', Gautam PL'1, Khullar Rubina', Paul Birinder S²
}

Paul Gunchan', Gautam PL', Khullar Rubina', Paul Birinder $\mathrm{S}^{2}$

'Department of Critical Care Medicine, Dayanand Medical College and Hospital, Ludhiana, Punjab, INDIA.

${ }^{2}$ Department of Neurology, Dayanand Medical College and Hospital, Ludhiana, Punjab, INDIA.

\section{Correspondence}

Dr. Gunchan Paul

Assistant Professor, Critical Care Medicine,

Dayanand Medical College and Hospital,

Ludhiana, Punjab, INDIA. 141001

Mobile no: $98786-45330$

Fax: 0161-2302620

Email: gunchan@gmail.com

History

- Submission Date: 13-07-2017

- Revised Date: 17-10-2017

- Accepted Date: 17-01-2018

DOI : 10.5530/ijmedph.2018.1.4

Article Available online

http://www.ijmedph.org/v8/i

Copyright

(c) 2018 Phcog.Net. This is an openaccess article distributed under the terms of the Creative Commons Attribution 4.0 International license.

\begin{abstract}
Background: Leaving against medical advice (LAMA) is a common but undesirable clinical situation seen worldwide. We planned to determine the incidence and factors responsible of LAMA in the emergency and intensive care unit of our multidisciplinary tertiary care hospital. Methods: All consecutive patients who left against medical advice from the emergency and surgical intensive care units were included in the study. We prospectively collected data on patients demographic profile, diagnosis, duration of hospital stay, reasons for DAMA and socio-economic status using the Kuppuswamy's Socio-Economic Status Scale (modified in 2014, Appendix1) to categorize the patient's socio-economic status. Results: The rate of DAMA from emergency and ICU was $2.4 \%$ and $15 \%$, respectively. The mean age of the study patients was $50.4+17.39$ years (range: $14-94$ years)) with a male-to-female ratio of $2: 1$. In our study findings the major reasons to leave DAMA in decreasing order of frequency were lack of improvement in patient's condition or terminal illness, financial constraints, attending to family matters, dis-satisfaction with treatment and tendency to seek alternative therapy. Dis-satisfaction with the management plan was more common in ICU than emergency $(p=0.00001)$. About $40 \%$ of the DAMA patients from emergency were semi-skilled and unskilled workers with an average income of $<10,000 /$ month whereas the average monthly income of patients going DAMA from ICU was up to $40,000 /$ month in all except $14.2 \%$ cases. In our study population, patients leaving the ICU were more educated $(p=0.000007)$ and belonged to the upper socioeconomic status $(p=0.46)$ as compared to those in emergency who mainly belonged to the upper lower class ( $p=0.0004)$. Conclusion: The number of people leaving AMA from the ICU is relatively high. To reduce LAMA rate, it is important to have a good knowledge of reasons for LAMA and understanding the problem in context to disease, outcome and socioeconomic status. Communication with the patient and family extensively with respect to all facets of care is the corner-stone to deal with this problem.

Key words: Left against medical advice, Discharge against medical advice, Emergency, Intensive care unit.

Key Message: The rate of patients leaving AMA is relatively higher from the ICU than the emergency department. The key solution to this problem is to understand the reasons for LAMA and have good communication with the patient and family in context to disease and outcome.
\end{abstract}

\section{INTRODUCTION}

The incidence of patients leaving the hospital before the treating physicians recommend their discharge is variously abbreviated as DAMA (discharge against medical advice), SAMA (signing against medical advice), LAMA (leaving against medical advice), or DOR (discharge on request). This phenomenon poses major clinical, ethical, and legal challenges to the individual physician as well as the hospital. ${ }^{1}$

These patients are often acutely ill at the time of self-discharge and have incompletely treated medical problems, hence remain exposed to high risks of mortality and morbidity. ${ }^{2,3,4}$ There is a high incidence of re-admission and complications accounting for higher costs of treatment. Therefore, avoiding the

clinical situation of DAMA will not only benefit the patients but also the health care system.

The most critical void in the literature on discharges against medical advice is the lack of understanding as to why patients choose to leave. Identifying these reasons is essential in designing of preventive interventions. Reasons for DAMA may be influenced by race/ethnicity, cultural factors, and faith in alternative forms of therapy, communication and relationship with the physician, financial issues and personal reasons. The prevalence rate is shown by some researchers to be higher in the developing than the developed countries, and ranges from $0.7 \%$ to $2.2 \%{ }^{5,6}$ Although this issue has been widely studied in the western world,

Cite this article : Gunchan P, Gautam PL, Rubina K, Birinder PS. Prospective Evaluation of Patients Leaving against Medical Advice of a Tertiary Care Hospital: Comparison of Emergency and Intensive Care Units. Int J Med Public Health. 2018;8(1):18-23. 
data from developing countries is sparse and mostly retrospective. Moreover, it has focused on patients leaving against medical device in specific populations with psychiatric, medical, and orthopedic disorders, and those with substance abuse. ${ }^{7}$ To the best of our knowledge, there is no study on DAMA in the emergency and intensive care units. Hence, the current study was planned to prospectively evaluate the cases of DAMA in a multidisciplinary intensive care unit of a tertiary care hospital and to develop strategies to reduce the incidence of this unwanted but relatively common clinical scenario.

\section{AIMS AND OBJECTIVES}

- To study the incidence of DAMA/ LAMA in the emergency and intensive care unit of a multidisciplinary tertiary care hospital

- To study the factors responsible for DAMA/ LAMA

\section{MATERIAL AND METHODS}

We conducted a prospective study on DAMA patients in the emergency and intensive care units of a tertiary care teaching hospital in North India. All consecutive patients who left against medical advice between $1^{\text {st }}$ April, 2016 and $31^{\text {st }}$ March, 2017 from the emergency and surgical intensive care units were included in the study. The study was approved by the institutional ethical committee (IEC).

According to the hospital policy, a request for DAMA is considered when a related form is signed by the patient or his legal custodian. A proforma for this study was designed on the basis of reasons reported by the patients in the past for self-discharges and was completed by the residents on duty in the intensive care unit and emergency department during that period. The data harvested included information on patients demographic profile, diagnoses, socio-economic status, duration of hospital stay (as per hospital policy, patient can stay up to seven days in the emergency unit), and reasons for DAMA. We also noted the patient's relationship with the person deciding DAMA, and his/her educational status in cases where the decision was not taken by the patient himself. We used Kuppuswamy's Socio-Economic Status Scale (modified in 2014, Appendix 1) to categorize the patient's socio-economic status.

The quantitative variables are presented as mean \pm SD (standard deviation) and categorical variables are summarized by absolute frequencies and percentages. Data was then analyzed using the statistical software SPSS version 16.0 for Windows (SPSS Inc., Chicago, IL). Data from the emergency and ICU was analyzed individually, and also compared with each other. Statistical significance was defined by a $\mathrm{p}$ value $\leq 0.05$.

\section{RESULTS}

During the twelve-month study period, there were 35636 emergency admissions and 1733 ICU admissions in our hospital among which 1116 patients were DAMA, 856 and 260 from the emergency and ICU respectively. This accounted for DAMA rates of $2.4 \%$ and $15 \%$ from emergency and ICU, respectively. Sixty-six patients were not ready to share information regarding socioeconomic status and their reasons to leave, so data could not be collected and were excluded from the study. Data of another 156 patients (12\%) were missing during collection, accounting for 893 patients that were finally included in the study. The demographic profile of these patients is depicted in Table 1. The mean age of patients going DAMA from the emergency and ICU was $50.39 \pm 17.39$ and $50.4 \pm 17.67$ years respectively (range: 14-94 years) with a male-to-female ratio of 2:1. Forty two percent $(n=375)$ of the patients were in the 41-60 year age group, and two-thirds of patients leaving DAMA were from rural areas. The mean length of stay was $2.32 \pm 5.17$ days in the emergency, and $7.7 \pm 6.5$ days in the ICU. Figure 1 demonstrates the frequency distribution of LOS in hospital. In comparison to the emergency group where $80.8 \%(n=565)$ patients had DAMA within 1-2 days of admission, the trend in ICU shows that $53.7 \%(n=44)$ patients left DAMA within the first week of ICU stay. About $40 \%$ of the patients from emergency were semi-skilled and unskilled workers with an average income of $<$ Rs.10,000/month, whereas the average monthly income of patients going DAMA from ICU was up to Rs.40,000/month in all except $14.2 \%$ cases. In the study population, patients leaving the ICU were more educated $(\mathrm{p}=0.0007)$ and belonged to the upper socioeconomic status $(\mathrm{p}=0.046)$ compared to those from the emergency who mainly belonged to the upper lower class. Only $4 \%$ of the total patients were covered by health insurance.

Though there was a wide range of diagnoses in patients going DAMA, infections and poly-trauma were the most common diagnoses in the emergency and ICU, respectively (Figure 2). The reasons for DAMA as stated by the patients are cited in Table 2 . The primary reason to get discharged against medical advice from the ICU was "lack of noticeable improvement in patient's condition when the patient had a terminal illness" in $44.7 \%$ and "financial constraints" in another $37.4 \%$ of patients. Financial constraints were the reason for patients to leave the emergency AMA in $37 \%$ cases. Dis-satisfaction with the management plan was more commonly reported in the ICU than in the emergency $(p=0.00001)$. Forty patients cited more than one reason for opting DAMA. In our study only two percent of patients made the decision themselves; in the remaining $98 \%$ cases, the decision was taken by the family members (either kin/spouse) as the patient may be too sick to take the decision.

\section{DISCUSSION}

This is the first prospective study on evaluation of incidence of patients who get discharged against medical advice from a tertiary care center in North India. We also analyzed the reasons for the same. Our study showed an incidence rate of DAMA of $2.4 \%$ and $15 \%$ from emergency and ICU, respectively. The results of this study were in contrast to the western data where a very low rate of $0.2 \%$ has been recorded, but comparable to statistics from developing countries where a rate of 3.5-5\% has been documented from the emergency unit. ${ }^{4,5,6}$ To the best of our knowledge, there is no data about DAMA from the intensive care unit in literature. The markedly high incidence of DAMA from intensive care unit may be multifactorial. Ours is a referral center, catering to large population of North India. Many patients are shifted from other hospitals when they become critical due to terminal illnesses, or following complications of therapy.

In our study cohort, the average age of patients from both emergency and ICU are comparable. However, it is of serious concern that $42 \%$ patients leaving DAMA were in the fifth-sixth decades of life that is the productive age-group for any country. Hence, more studies are needed not only to identify the common reasons that compel the patients to get DAMA but also reduce the rate of DAMA.

Our results match with some studies that report male gender and younger age as some of the demographic factors that are frequently associated with DAMA. ${ }^{8,9,10,11}$ The reason for male preponderance in these studies could be the selection bias in study population as they mainly included patients suffering from cardiac disease and trauma. ${ }^{12,13}$ In the current study also, the most common diagnosis in patients opting for DAMA was poly- trauma. Secondly, a paternalistic family structure of Indian families which leads to a general pattern of more health concerns and hospital admissions among males whereas health concerns of females are much neglected. Naderi $\mathrm{S}$ et al from India have also cited gender as the cause of many social issues including health care. ${ }^{14}$

Based on the patient population and the type of therapy, the rate of DAMA differs widely, and as previously suggested, patients with chronic medical conditions may be at a higher risk for DAMA. ${ }^{15,16}$ In our study, the major reasons to leave DAMA in decreasing order of frequency were 
Table1: Demographic profile of the study population.

\begin{tabular}{|c|c|c|c|}
\hline \multirow[b]{2}{*}{ Characteristic } & \multicolumn{3}{|c|}{ Group; no. $(\%)$ of DAMA patients } \\
\hline & Emergency $(n=703)$ & $\operatorname{ICU}(n=190)$ & \\
\hline Mean Age (y) & $50.39+17.39$ & $50.4+17.67$ & \\
\hline \multicolumn{4}{|l|}{ Age Category (y) } \\
\hline$<18$ & $21(3.0)$ & $3(1.6)$ & \\
\hline $18-30$ & $89(6.4)$ & $25(13.2)$ & \\
\hline $31-40$ & $89(6.4)$ & $25(13.2)$ & \\
\hline $41-50$ & $145(20.6)$ & $39(20.5)$ & \\
\hline $51-60$ & $153(21.8)$ & $38(20)$ & \\
\hline $61-70$ & $130(18.5)$ & $41(21.6)$ & \\
\hline $71-80$ & $45(6.4)$ & $16(8.4)$ & \\
\hline$>80$ & $31(4.4)$ & $3(1.6)$ & \\
\hline \multicolumn{4}{|l|}{ Sex } \\
\hline Male & $227(32.3)$ & $71(37.4)$ & \\
\hline Female & $476(67.7)$ & $119(62.6)$ & \\
\hline \multicolumn{4}{|l|}{ Religion } \\
\hline Hindu & $336(47)$ & $78(41.1)$ & \\
\hline Muslim & $24(3.3)$ & $3(1.6)$ & \\
\hline Sikh & $341(48.5)$ & $109(57.4)$ & \\
\hline Christian & $2(0.3)$ & $0(0)$ & \\
\hline \multicolumn{4}{|l|}{ Occupation } \\
\hline Unemployed & $144(20.5)$ & $29(15.3)$ & \\
\hline Unskilled worker & $132(18.8)$ & $16(8.4)$ & \\
\hline Semi-skilled worker & $146(20.8)$ & $38(20)$ & \\
\hline Skilled worker & $89(12.7)$ & $31(16.3)$ & \\
\hline Clerical, Shopkeeper, Farmer & $103(14.7)$ & $33(17.4)$ & \\
\hline Semi-professional & $47(6.7)$ & $27(14.2)$ & \\
\hline Professional & $42(7.0)$ & $6(8.4)$ & \\
\hline \multicolumn{4}{|l|}{ Monthly income } \\
\hline$<1865$ & $34(4.8)$ & $1(0.5)$ & \\
\hline $1866-5546$ & $201(28.6)$ & $13(6.7)$ & \\
\hline $5547-9,248$ & $130(18.5)$ & $15(7.7)$ & \\
\hline $9,249-13,873$ & $98(13.9)$ & $24(12.6)$ & \\
\hline $13,874-18,497$ & $106(15.1)$ & $46(24.2)$ & \\
\hline $18,498-36,996$ & $111(15.8)$ & $64(33.7)$ & \\
\hline$>36,997$ & $23(3.3)$ & $27(14.2)$ & \\
\hline \multicolumn{4}{|l|}{ Education Status } \\
\hline Illiterate & $57(8.1)$ & $18(9.5)$ & \\
\hline Primary school & $75(10.7)$ & $12(6.3)$ & \\
\hline Middle school & $77(11)$ & $32(16.8)$ & \\
\hline High school & $188(26.7)$ & $43(22.6)$ & \\
\hline Post high school Diploma & $101(14.4)$ & $28(14.7)$ & \\
\hline Graduate or Post-graduate & $195(27.7)$ & $43(22.6)$ & \\
\hline Professional/Honors & $10(1.4)$ & $14(7.4)$ & 0.0007 \\
\hline \multicolumn{4}{|l|}{ Socioeconomic Status Group } \\
\hline Lower class & $28(4)$ & $5(2.6)$ & \\
\hline Lower middle class & $231(32.9)$ & $58(30.5)$ & \\
\hline Upper lower class & $279(39.7)$ & $30(15.8)$ & \\
\hline Upper middle class & $140(19.9)$ & $84(44.2)$ & \\
\hline Upper class & $25(3.6)$ & $13(6.8)$ & 0.046 \\
\hline
\end{tabular}




\begin{tabular}{|c|c|c|c|c|c|}
\hline \multirow{2}{*}{ Reasons for DAMA } & \multicolumn{2}{|c|}{ EMERGENCY $(n=703)$} & \multicolumn{2}{|c|}{$\operatorname{ICU}(n=190)$} & \multirow{2}{*}{$P<0.05$} \\
\hline & (n) & (\%) & (n) & $(\%)$ & \\
\hline 1.Use of alternative therapy & 52 & $7.4 \%$ & 14 & $7.4 \%$ & 0.989 \\
\hline 2. Feeling of wellness & 66 & $9.4 \%$ & 3 & $1.6 \%$ & 0.0003 \\
\hline 3. No improvement or terminal illness & 164 & $23.3 \%$ & 85 & $44.7 \%$ & 0.00002 \\
\hline 4.Lack of consent for surgery & 13 & $1.8 \%$ & 6 & $3.2 \%$ & 0.267 \\
\hline 5.Attending to family matters & 90 & $12.8 \%$ & 9 & $4.7 \%$ & 0.001 \\
\hline 6.Dis satisfaction with present plan of management & 12 & $1.7 \%$ & 15 & $7.9 \%$ & 0.00001 \\
\hline 7.Financial constrains & 260 & $37.0 \%$ & 71 & $37.4 \%$ & 0.923 \\
\hline 8.Unspecified & 61 & $8.7 \%$ & 11 & $5.8 \%$ & 0.195 \\
\hline
\end{tabular}

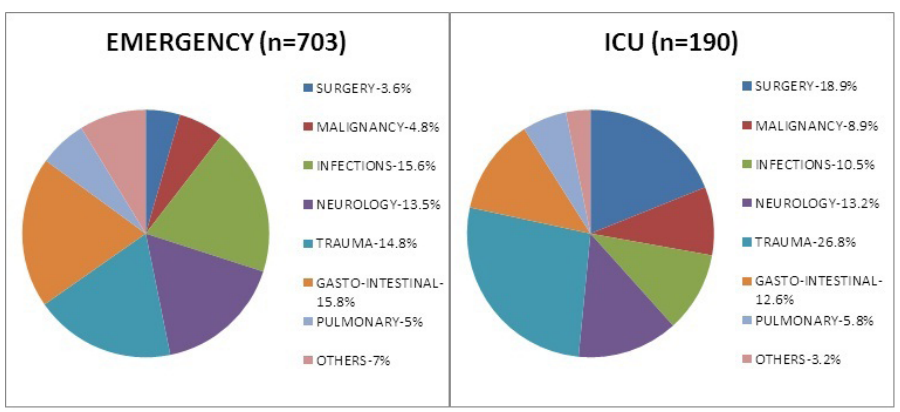

Figure 1: Diagnosis of patients leaving against medical advice (DAMA).

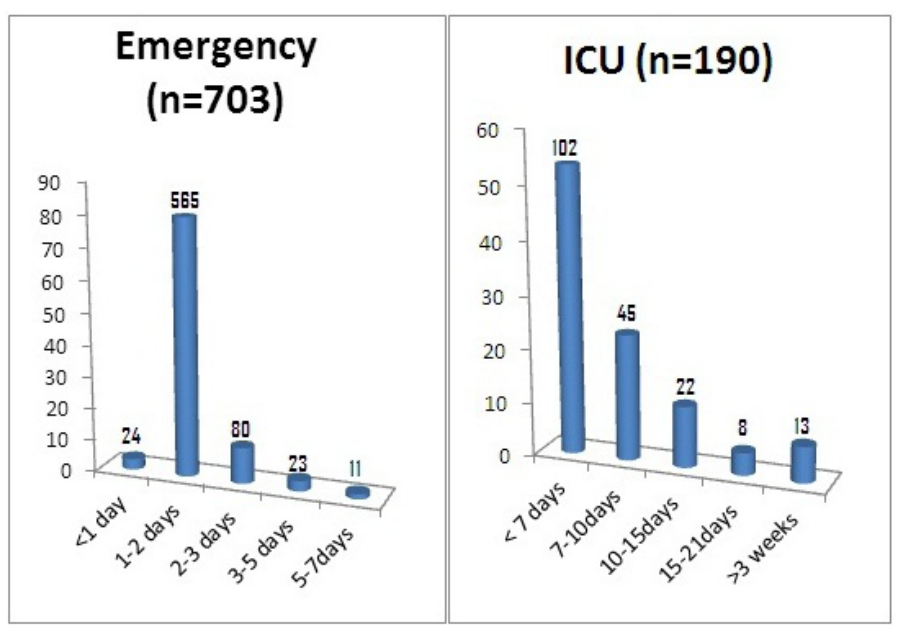

Figure 2: Frequency distribution of length of stay before patient's leave against medical advice (DAMA).

lack of improvement in patient's condition or terminal illness, financial constraints, attending to family matters (such as marriages and religious festivals), dis-satisfaction with treatment and tendency to seek alternative therapy.

The major reason to leave DAMA from the ICU in our study was lack of improvement in patient's condition or terminal illness in $44 \%$ cases. Hence, concluding that when patients with terminal illness or in critical situations are shifted from wards or emergency to the ICU and after resuscitation and re-evaluation in the ICU if there is no significant

\section{Appendix 1}

Kuppuswamy's socioeconomic status scale

\begin{tabular}{|c|c|c|c|c|}
\hline (A) & \multicolumn{3}{|l|}{ Education } & Score \\
\hline 1 & \multicolumn{3}{|l|}{ Profession or honors } & 7 \\
\hline 2 & \multicolumn{3}{|c|}{ Graduate or post graduate } & 6 \\
\hline$s$ & \multicolumn{3}{|c|}{ Intermediate or post high school diploma } & 5 \\
\hline 4 & \multicolumn{3}{|c|}{ High school certificate } & 4 \\
\hline 5 & \multicolumn{3}{|c|}{ Middle school certificate } & $s$ \\
\hline 6 & \multicolumn{3}{|c|}{ Primary school certificate } & 2 \\
\hline$\underline{7}$ & \multicolumn{3}{|c|}{ Illiterate } & 1 \\
\hline (B) & \multicolumn{3}{|l|}{ Occupation } & Score \\
\hline 1 & \multicolumn{3}{|l|}{ Profession } & 10 \\
\hline 2 & \multicolumn{3}{|l|}{ Semi-profession } & 6 \\
\hline$s$ & \multicolumn{3}{|c|}{ Clerical, shop-owner, farmer } & 5 \\
\hline 4 & \multicolumn{3}{|c|}{ Skilled worker } & 4 \\
\hline 5 & \multicolumn{3}{|l|}{ Semi-skilled worker } & $s$ \\
\hline 6 & \multicolumn{3}{|l|}{ Unskilled worker } & 2 \\
\hline 7 & \multicolumn{3}{|l|}{ Unemployed } & 1 \\
\hline (C) & $\begin{array}{c}\text { Family income } \\
\text { per month (in Rs.) } \\
\text { - original }\end{array}$ & Score & $\begin{array}{l}\text { Modified } \\
\text { for } 1998\end{array}$ & $\begin{array}{l}\text { Modified } \\
\text { for } 2007\end{array}$ \\
\hline 1 & $=2000$ & 12 & $=15,500$ & $=19,575$ \\
\hline 2 & $1000-1999$ & 10 & $6750-15,499$ & $9788-19,574$ \\
\hline$s$ & $750-999$ & 6 & $5050-6749$ & $7525-9787$ \\
\hline 4 & $500-749$ & 4 & $5575-5049$ & $4894-7522$ \\
\hline 5 & $500-499$ & $s$ & $2025-5574$ & $2956-4895$ \\
\hline 6 & $101-299$ & 2 & $676-2024$ & $980-2955$ \\
\hline 7 & $=100$ & 1 & $=675$ & $=979$ \\
\hline \multicolumn{2}{|c|}{ Total score } & \multicolumn{3}{|c|}{ Socioeconomic class } \\
\hline \multicolumn{2}{|c|}{$26-29$} & \multicolumn{2}{|r|}{ Upper (1) } & \\
\hline \multicolumn{2}{|c|}{$16-25$} & \multicolumn{2}{|r|}{ Upper-middle (I) } & \\
\hline \multicolumn{2}{|c|}{ 11-15 Middle } & \multicolumn{3}{|c|}{ Lower-middle (III) } \\
\hline \multicolumn{2}{|c|}{ 5-10 Lower } & \multicolumn{2}{|r|}{ Upper-lower (IV } & \\
\hline \multicolumn{2}{|c|}{$<5$} & \multicolumn{2}{|c|}{ Lower $(\mathrm{V})$} & \\
\hline
\end{tabular}

improvement in patient's condition, they decide to leave DAMA when explained about the prognosis of the patient's condition.

Financial constraint was the second most common reason cited by patients to leave against doctor's advice. ${ }^{17,18,19}$ Naderi $S$ et al , report 
the frequency of patients leaving the hospital ED for financial reasons among the highest found in the literature, i.e.,84\% went DAMA as the hospital bill exceeded $25 \%$ of their annual income. Our results echo with such studies as the average income of our patients was quiet low, both in the emergency and ICU, accounting to early peaks of DAMA i.e. within 2 days from emergency and within first week from ICU. However, this data regarding patient's socioeconomic status was based on verbal report of the person signing the DAMA proforma, without documented evidence. Secondly, ours is a tertiary care referral center and patients referred from other hospitals might have already exhausted their resources and choose to leave DAMA early, after a second opinion. This could also be contributed to the lack of awareness of health insurance, as only $4 \%$ patients in our cohort were insured. Also there is an absence of facility of National Health Insurance Scheme (NHIS) in our country, and the majority of our population bear the cost of treatment themselves (out of pocket expenses). The general scenario is that even in critical situations and emergencies, the patient might be initially stabilized at the point of first care, and families must then, decide whether to pay for further services, transport the patient to a government hospital, or forego further care.

Contrary to a previous report from a general hospital, our analysis of the reasons revealed that social factors (e.g., attending to family issues and financial matters) rather than medical factors (e.g. lack of consent for procedure), were more common reason for DAMA among the study population. ${ }^{20}$ Though many others had personal reasons documented, but they were difficult to believe and might have been merely excuses for discharge from the hospital.

Consonant with some previously conducted research; yet another justification for DAMA is a disagreement with the physician's judgment of their health status. ${ }^{21}$ In this study, about $8 \%$ of patients who went DAMA were dissatisfied with the management plan. This might be due to gaps in physician-patient communication that leaves the patient with insufficient information regarding his or her illness, its complications and prognosis, and available treatment modalities. This is more common in the ICU than emergency because as the patient stays longer in the hospital, the financial burden increases, and also the increasing frustration of the family especially if the patient is not doing well. It is a general human tendency to find flaws in the system than to accept the reality which leads to dis-satisfaction and the option to leave as DAMA.

Lastly, another reason noted for DAMA on the part of trauma patients was seeking alternative therapy (7.4\%) from traditional bone-setters due to multiple reasons like fear of surgery or amputation, lower costs, and greater faith in traditional healing methods.

There are a few limitations of this study. Firstly, there is no control group to compare DAMA patients with those who are discharged normally. Secondly, due to the large number we were unable to follow-up these patients to determine the outcome of DAMA, i.e, whether they were re-admitted to our hospital or other hospitals, or died. Thirdly, data of about $20 \%$ patients were missing during the one year study period. And finally, it is a single center study, so the conclusions of the present study may be generalizable to others with caution.

In conclusion, the percentage of patients leaving DAMA from our super-specialty hospital in India is very high. Although many leave due to financial reasons which can be dealt by strengthening the National Health Insurance Scheme, this survey suggests that there are other reasons also, which if taken proper notice of, can help decrease the magnitude of the problem. Improving physician-patient relationship is the corner-stone to deal with this problem. Analysis of the patients current circumstances, direct communication of need to continue hospital stay, involving family in decision making, compassion towards the difficulties associated with being in hospital can prevent some of the discharges against medical advice. Secondly, focused health education on the benefits of medicine and care rather than traditional form of therapy is another strategy to reduce DAMA.

\section{CONCLUSION}

The number of people leaving AMA from the ICU is relatively high. To reduce LAMA rate, it is important to have a good knowledge of reasons for LAMA and understanding the problem in context to disease, outcome and socioeconomic status. Communication with the patient and family extensively with respect to all facets of care is the corner-stone to deal with this problem.

\section{ACKNOWLEDGEMENT}

we acknowledge the cooperation of our patients and their families without which this project would not have reached completion.

\section{ABBREVIATIONS USED}

AMA: Against medical advice; DAMA: Discharge against medical advice; LAMA: Leaving against medical advice; ICU: Intensive care unit; LOS: Length of stay; ED: Emergency department.

\section{CONFLCIT OF INTEREST}

The authors declare no conflict of interest.

\section{REFERENCES}

1. Alfandre D J. 'I'm going home': discharges against medical advice," Mayo Clinic Proceedings. 2009;84:255-60.

2. Jeremiah J, O'Sullivan $P$, Stein M. Who leaves against medical advice? J Gen Intern Med. 1995;10(7):403-5.

3. Hwang S W, Li J, Gupta R, Chien V et al. "What happens to patients who leave hospital against medical advice?" Canadian Medical Association Journal. 2003;168(4):417-20

4. Southern WN, Nahvi S, Arnsten JH: Increased risk of mortality and readmission among patients discharged against medical advice. Am J Med. 2012;125(6): 594-602.

5. Dubow D, Propp D, Narasimham K: Emergency department discharges against medical advice. J Emerg Med. 1992;10(4):513-6.

6. Nasir AA, Babalola OM: Clinical spectrum of discharges against medical advice in a developing country. Indian J Surg. 2008;70(2):68-72

7. Wong TW, Lee KM, Chan R, Lau CC: A Study of patients who leave an accident and emergency department against medical advice. Hong Kong J Emerg Med. $2000 ; 7(1): 22-6$

8. Aliyu ZY. "Discharge against medical advice: sociodemographic, clinical and financial perspectives," International Journal of Clinical Practice. 2002;56(5): 325-7.

9. Green P, Watts D, Dhopesh. "Why patients sign out against medical advice (AMA): factors motivating patients to sign out AMA," The American Journal of Drug and Alcohol Abuse. 2004;30(2):489-93.

10. Udosen AM, Glen E, Ogbudu S, Nkposong E. "Incidence of leaving against medical advice (LAMA) among patients admitted at the accident and emergency unit of the University of Calabar Teaching Hospital, Calabar, Nigeria," Nigerian Journal of Clinical Practice. 2006;9(2):120-3.

11. Franks $P$, Meldrum S, Fiscella K. Discharges against medical advice: are race/ ethnicity predictors? Journal of General Internal Medicine. 2006;21(9):955-60.

12. Manouchehr J, Goodarzy nejad H, Khoshgoftar Z, Sheikh Fathollahi M, Abyaneh AM. Discharge against Medical Advice among Inpatients with Heart Disease in Iran. J Tehran Heart Cent. 2012;7(2):72-7.

13. Fiscella K, Meldrum S, Barnett S. Hospital discharge against advice after myocardial infarction: deaths and readmissions. The American Journal of Medicine. 2007; 120(12):1047-53.

14. Orimolade E A, Adegbehingbe O O, Oginni L M, Asuquo J E, Esan O. Reasons why trauma patients request for discharge against medical advice in Wesley Guild Hospital Ilesha. East and Central African Journal of Surgery. 2013;18(3): 71-5.

15. Baptist AP, Warrier I, Arora R, Ager J, Massanari R M. Hospitalized patients with asthma who leave against medical advice: characteristics, reasons, and outcomes. Journal of Allergy and Clinical Immunology. 2007;119(4):924-9.

16. Duno R, Pousa E, Sans J, Tolosa C, Ruiz A. Discharge against medical advice at a general hospital in Catalonia. Gen Hosp Psychiatry. 2003;25(1):46-50. 
17. Jimoh BM, Anthonia OC, Chinwe I, et al. Prospective Evaluation of Cases of Discharge against Medical Advice in Abuja, Nigeria The Scientific World Journal. 2015;1-4.

18. Okoromah C N, Egri-Qkwaji M T. Profile of and control measures for paediatric discharges against medical advice. The Nigerian Postgraduate Medical Journal. 2004; $11(1): 21-5$.

19. Naderi S, Acerra J R, Bailey K et al. Patients in a private hospital in India leave the emergency department against medical advice for financial reasons. International Journal of Emergency Medicine. 2014;7(1):13.

20. Lorenzi E, Da RC, Lorenzoni L, Massaria G, Aparo U L. Characteristics of voluntarily discharged patients: some reflections and a proposal. Annali di Igiene. 2000;12(6):513-21.

21. Smith DB, Telles JL. Discharges against medical advice at regional acute care hospitals. Am J Public Health. 1991;81(2):212-5.

Cite this article : Gunchan P, Gautam PL, Rubina K, Birinder PS. Prospective Evaluation of Patients Leaving against Medical Advice of a Tertiary Care Hospital: Comparison of Emergency and Intensive Care Units. Int J Med Public Health. 2018;8(1):18-23. 